children with coeliac disease. Multiple small intestinal biopsy specimens, perhaps taken endoscopically, may be helpful in establishing the presence of intestinal lymphangiectasia in children with coeliac disease. ${ }^{36}$ As intestinal lymphangiectasia may be an incidental finding, additional data, for example the presence of hypoimmunoglobulinaemia and $\mathrm{T}$ cell depletion, may help in determining the clinical significance of lymphangiectatic mucosal changes. ${ }^{5} 6$ These patients with coeliac disease need lifelong diet management.
The authors thank Dr Ian W Booth for his contribution to this manuscript.

1 Cooke WT, Holmes GKT. Coeliac disease and associated disorders. In: Cooke WT, Holmes GKT, eds. Coelia disease. Edinburgh: Churchill Livingstone, 1984:225-46.

2 Goodchild MC, Nelson R, Anderson CM. Cystic fibrosis and coeliac disease: coexistence in two children. Arch Dis Child 1973;48:684-91.

3 Meeuwisse GW. Diagnostic criteria in coeliac disease. Acto Paediatr Scand 1970;59:461-3.

4 King EJ. Microanalysis in medical biochemistry. London: Churchill, 1953;92-6.

5 Vardy PA, Lebenthal E, Shwachman H. Intestinal lymphangiectasia: a reappraisal. Pediatrics 1975;55:842-51. 6 Walker-Smith JA. Protein losing enteropathies. In: WalkerSmith JA, ed. Diseases of the small intestine in childhood. London: Butterworth, 1988:420-5.

\title{
Positive end expiratory pressure via a portable system in thoracic dystrophy
}

\author{
S Edees, A Moulden, R J Winter
}

\begin{abstract}
The provision of positive end expiratory pressure, via a unique portable system, in the long term management of a child with thoracic dystrophy is reported. The system uses low gas flow enabling a reduction in equipment and simplification of the circuit as compared with a standard continuous positive airways pressure system.
\end{abstract}

For a child requiring long term continuous positive airways pressure (CPAP), we devised a system for providing positive end expiratory pressure (PEEP) using low flows of oxygen. The system, initially employed to provide CPAP, was a standard high flow Bennett system necessitating that the patient be restricted to his cot on the infants' ward where there are piped supplies of oxygen and air. In order for him to become mobile around the hospital and ultimately at home, we devised a portable PEEP system.

\section{Description of the system}

Our system (figure) employed the same CPAP valve and $T$ piece as the high flow pipeline

University Hospital, Nottingham NG7 2UH, Department of Child Health $S$ Edees

A Moulden

Department of

Anaesthesia

R J Winter

Correspondence to:

Dr Winter.

Accepted 3 September 1991

(Arch Dis Child 1992;67:136-7)

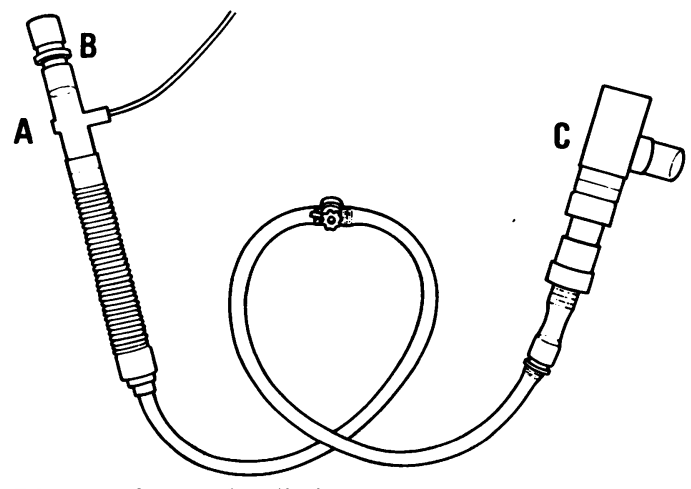

Diagram of system described. system but required a mixer with a non-return valve to allow the use of low flow oxygen without loss of the PEEP from the valve and to prevent rebreathing. The system consisted of a $T$ piece with an oxygen connector (A) in series with a 1950 non-return valve (B) on one limb, and the CPAP valve $(C)$ on the other limb, the assembly being connected to the infant by a standard $15 \mathrm{~mm}$ Portex connector.

The inspired oxygen delivered by the system depends upon the flow of oxygen into the circuit, the respiratory rate, and the inspiratory flow rate of the patient. An increase in the respiratory rate will reduce the time available for oxygen to accumulate in the wide bore tubing during expiration and therefore reduce the fractional inspired oxygen $\left(\mathrm{FiO}_{2}\right)$. An increase in inspiratory flow will increase the volume of room air entrained via the 1950 one way valve reducing the $\mathrm{FIO}_{2}$. Therefore, the oxygen tension in the circuit cannot be accurately predicted from the present oxygen flow; however, we have found that a flow of $500 \mathrm{ml} / \mathrm{min}$ delivers approximately $28 \%$ oxygen to our patient. Increasing the flow of oxygen to the circuit up to $11 / \mathrm{min}$ increases the $\mathrm{FIO}_{2}$ to $36 \%$, and $21 / \mathrm{min}$ to $48 \%$. Rebreathing is prevented by the presence of the 1950 one way valve and also by the one way valve in the CPAP valve. As flow in the circuit is generated by the child's inspiratory effort the system provides PEEP, not CPAP.

\section{Case report}

Soon after birth our patient, now aged 18 months, was noted to have a number of dysmorphic features including the Pierre Robin syndrome (cleft of the soft palate, micrognathia, and glossoptossis), macrocephaly, severe hyphoscoliosis, a small thorax, a penile web attached to the scrotum, and generalised hypotonia.

Investigations were carried out to evaluate his 
dysmorphology. His chest radiograph showed short flat ribs with a bell shaped thorax, but no posterior rib defects. Lung function tests at 5 months of age confirmed small volume lungs (total gas volume $25 \mathrm{ml} / \mathrm{kg}$ ) with a restrictive pattern and a small component of airways obstruction (airway resistance 39.6 to $51 \mathrm{~cm}$ $\mathrm{H}_{2} \mathrm{O} / 1 / \mathrm{sec}$ ). Serial chest radiographs from 3 months to the present have shown little chest growth, with significant atelectasis present at most times. Skeletal survey showed no abnormality of the skull, long bones, or pelvis. These investigations confirm our clinical impression of a thoracic dystrophy, and our search continues in order to define the underlying syndrome.

From birth our patient had respiratory difficulties with persistent tachypnoea and recession and recurrent episodes of pneumonia. At 9 months, respiratory failure ensued necessitating assisted ventilation. A tracheotomy was performed on day 8 as attempts at extubation had failed due to upper airway compromise. He was weaned on to CPAP $(5 \mathrm{~cm})$ on day 14 , requiring $30 \%$ oxygen via a tracheostomy mask to maintain oxygen saturations above $92 \%$. Soon after the CPAP was discontinued frequent episodes of desaturation occurred, which responded to manual positive pressure. CPAP was restarted using a high flow air-oxygen mix via a Bennett humidifier on the inspiratory limb and a CPAP valve on the expiratory limb until desaturation ceased. It was decided to provide long term PEEP after withdrawal on a number of occasions led to recurrent episodes of desaturation.

\section{SYSTEM EFFICACY}

After the patient was put onto our system and transferred to a general ward, he remained well. His arterial oxygen tension was maintained at between 9 and $11 \mathrm{kPa}$ and his arterial carbon dioxide tension $\left(\mathrm{PaCO}_{2}\right)$ remained in the range of 5.5 to $6.5 \mathrm{kPa}$. There was no rise in the $\mathrm{PaCO}_{2}$ after introduction of the system nor was there any increase in the respiratory rate.

\section{Discussion}

There are several of conditions which affect the skeleton and result in abnormal growth of the thorax. The majority of these conditions are rare and experience of management in individual centres is small.

We have been unable to attach an acceptable diagnostic label to this child's collection of dysmorphic features, and any assessment of his future respiratory function can only be guided by general principles. It has been suggested that the natural history of 'small chests' is for the problems to be most severe in the early months of life with gradual resolution if the child survives. ${ }^{1}$ The degree of respiratory compromise varies widely between patients even within the same diagnostic groupings.

The rationale for the use of PEEP was to reduce peripheral alveolar collapse and the subsequent ventilation/perfusion mismatch at the end of expiration. The use of long term positive pressure has been previously reported in thoracic dystrophy. ${ }^{2}$ In addition to his small chest wall, our patient also has a kyphoscoliosis. In adult patients with this condition lung compliance increases with positive pressure ventilation. $^{3}$

Because the device we have employed uses low flows of oxygen it allows his parents to take the child out of the hospital environment with only a D size oxygen cylinder. ${ }^{4}$ It would also be possible to provide flows of this magnitude by using an oxygen concentrator of the type normally used to deliver domiciliary oxygen, ${ }^{5}$ so allowing home management.

1 Hull D, Barnes ND. Children with small chests. Arch Dis Child 1972;47:12-9.

2 Wiebicke W, Pasterkamp H. Long term continuous positive airway pressure in a child with asphyxiating thoracic dystrophy. Pediatr Pulmonol 1988;4:54-8.

3 Sinha R, Bergofsky EH. Prolonged alteration of lung mechanics in kyphoscoliosis by positive pressure hyperventilation. Am Rev Respir Dis 1972;106:47-57.

4 Southall DP, Samuels MP. Bronchopulmonary dysplasia: a new look at management. Arch Dis Child 1990;65:1089-95. Bardesley P, Howard P. Oxygen concentrator in the home. BMF 1988;297:1486-7. 